\title{
Experimental Studies on Thermal Performance of a Pulsating Heat Pipe with Methanol/DI Water
}

\author{
Bhawna Verma*, Vijay Lakshmi Yadav, Kaushal Kumar Srivastava \\ Department of Chemical Engineering, Indian Institute of Technology, Banaras Hindu University, Varanasi, India \\ Email: "bverma.che@itbhu.ac.in
}

Received January 20, 2013; revised February 22, 2013; accepted March 1, 2013

\begin{abstract}
The effect of working fluid on the start-up and thermal performance in terms of thermal resistance and heat transfer coefficient of a pulsating heat pipe have been studied in the present paper. Methanol and de-ionized water has been selected as the working fluid. The minimum startup power for DI water was obtained at $50 \%$ filling ratio and for methanol at $40 \%$. The optimum filling ratio in terms of minimum startup power and minimum thermal resistance was $50 \%$ for DI water and $40 \%$ for methanol. The minimum thermal resistances for DI water and methanol were observed at vertical orientation. The evaporator side heat transfer coefficient for water was slightly more, while the condenser side heat transfer coefficient was appreciably more than that of methanol. Studies were also conducted for start-up time and temperature at different orientations and it was found that the PHP charged with methanol worked efficiently at all orientations.
\end{abstract}

Keywords: Pulsating Heat Pipe; Start-Up Power; Working Fluid; Thermal Resistance; Heat Transfer Coefficient

\section{Introduction}

With the rapid development in electronic industry, including the dramatic increase in chip density and power density, as well as continuous decrease in the physical size of electronic packages, the thermal management has become, and will continue to be one of the most critical technologies in the electronic product development. The pulsating/oscillating heat pipe (PHP/OHP) first proposed by Akachi [1] in 1990 is a new type of efficient heat transfer device which has shown promising results for electronic cooling. It is drawing a great deal of attention due to its simple design, small size and excellent thermal performance. It is different from a traditional heat pipe in working and design. A typical PHP is made of a long continuous capillary tube bent in serpentine manner in many turns. It is first evacuated and then filled partially with a working fluid. Working Fluid distributes itself in the form of liquid-vapor plugs and slugs. The inner diameter of the pipe must be sufficiently small so that vapor bubbles can grow to vapor plugs in the tube. The theoretical maximum diameter (based on balance of capillary and gravity forces) is given by [2]:

$$
D_{\text {max }}=2\left[\sigma /\left(\rho_{\text {liq }}-\rho_{\text {vap }}\right) g\right]^{1 / 2}
$$

The performance of a PHP depends upon many factors

${ }^{*}$ Corresponding author. like the geometrical parameters of flow channel, the working fluid, the filling ratio, and number of turns, PHP configuration and the inclination angle [3]. It can be designed in three ways 1) open loop system, 2) closed loop system and 3) closed loop with check valves.

In recent years, many experimental studies have been conducted to understand the mechanism of PHP and the factors affecting the performance of PHP. Numerous works had been reported on the effect of various factors like dimensions [4,5], tilt angles [6], number of turns [5], and filling ratio $[7,8]$, etc. Apart from these parameters, the choice of working fluid is very important. Water, organic solvents and refrigerants have been widely used as working fluid. Nanofluid has been reported to enhance the thermal performance of PHP [9]. The working fluid should have high $(\mathrm{d} p / \mathrm{d} T)_{\text {sat }}$, so that a small change in $T_{e}$ generates a large corresponding $P_{\text {sat }}$ inside the generated bubble which aids in the bubble pumping action of the device. It should also have low dynamic viscosity and low surface tension so that additional shear stress and pressure drop can be avoided. Khandekar et al. [10] reported that ethanol, water and R123 show efficient thermal performance while in vertical mode whereas none of these working fluids were suitable for horizontal mode of PHP operation. Liu [11] showed that in vertical orientation enhanced performance of PHP will be obtained due to increased circulatory flow if the flow geometry path is made less symmetric; ethanol was used as the working 
fluid. Lin et al. used acetone and concluded that better performance could be achieved in horizontal orientation [12]. On comparing FC-72 and FC-75, better performance was obtained by FC-72 [13]. Reihl [14] compared the performance of acetone, ethanol, isopropyl alchohol, methanol and water for open loop pulsating heat pipe and found that acetone works best in vertical orientation and methanol in horizontal orientation. Majority of the work available in open literature focuses on the effect of working fluid on thermal performance of the device. Very little work has been done to study the effect of working fluid on the start-up parameters of the PHP. Tong et al. [15] were the first to explain the importance of start-up and the phenomena in detail. They used methanol as the working fluid and concluded that startup can be achieved at a filling ratio of $60 \%$. Xu and Zhang [16] found $25 \mathrm{~W}$ as the startup power for PHP charged with FC-72, but FC-72 was efficient only for low heat inputs. Vassilev et al. [17] studied the effect on startup in square cross-section with methanol and water as working fluid. $\mathrm{Hu}$ and Jia [18] studied the startup characteristics of a flat plate pulsating heat pipe with ethanol and found that the startup depends on the heat load and filling rate. Wang et al. [19] compared the performance of DI water and acetone on a copper PHP with respect to startup and found that compared with distilled water, the PHP was more readily to be started with acetone as working fluid.

In view of the technological importance of the startup and thermal performance of pulsating heat pipe, the present work has been focused on studying the effect of working fluid on the start-up and thermal performance of a PHP in terms of heat transfer coefficient and the thermal resistance offered by it. Water has been found to be one of the best working fluid in terms of thermal performance of device under gravitational force. Methanol has the highest purity and the air dissolved in the liquid can be neglected. Hence, the methanol and de-ionized water has been selected as the working fluid for PHP. The thermophysical properties of the working fluids are given in Table 1.

\section{Experimental Apparatus and Method}

\subsection{Experimental Setup}

As shown in Figure 1, the PHP was fabricated by bending copper tubes (internal diameter $1.45 \mathrm{~mm}$, outer diameter

Table 1. Thermophysical properties of the working fluids.

\begin{tabular}{|c|c|c|c|c|c|c|c|}
\hline \multirow{2}{*}{ Working fluid } & \multicolumn{2}{|c|}{$P_{\text {sat }}$ (bar) } & \multicolumn{2}{|c|}{ Density $\rho_{\mathrm{l}}\left(\mathrm{kg} / \mathrm{m}^{3}\right)$} & \multirow{2}{*}{$\begin{array}{l}\mu_{\text {liq }}\left(\mathrm{Ns} / \mathrm{m}^{2}\right) \\
\left(T_{e}+T_{c}\right) / 2\end{array}$} & \multirow{2}{*}{$\begin{array}{l}C p_{\text {liq }}(\mathrm{J} / \mathrm{kg} \cdot \mathrm{K}) \\
\left(T_{c}+T_{e}\right) / 2\end{array}$} & \multirow{2}{*}{$\begin{array}{l}(\mathrm{d} P / \mathrm{d} T)_{\mathrm{sa}} \\
(\mathrm{bar} / \mathrm{K})\end{array}$} \\
\hline & $T_{c}\left(25^{\circ} \mathrm{C}\right)$ & $T_{e}\left(100^{\circ} \mathrm{C}\right)$ & $T_{c}\left(25^{\circ} \mathrm{C}\right)$ & $T_{e}\left(100^{\circ} \mathrm{C}\right)$ & & & \\
\hline Methanol & 0.1741 & 3.5367 & 780 & 723 & $516.8 e^{-} 6$ & $2.809 \mathrm{e}+3$ & 0.045 \\
\hline DI water & 0.0317 & 1.0132 & 997 & 958 & $453.2 \mathrm{e}-6$ & $4.183 \mathrm{e}+3$ & 0.013 \\
\hline
\end{tabular}

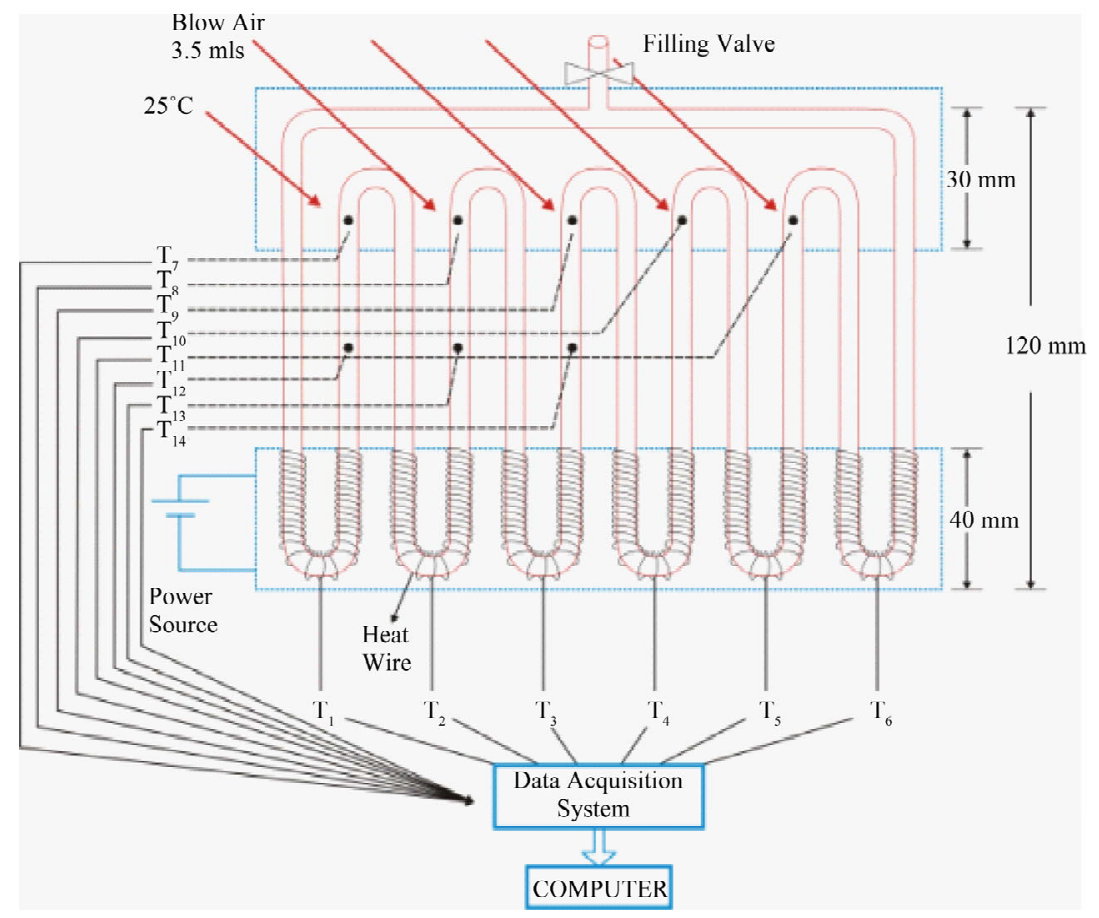

Figure 1. Schematic of experimental set-up. 
$2.54 \mathrm{~mm}$ with 6 turns). Nichrome resistance wire was wrapped around the bottom section of tubes, the evaporator. The evaporator was at the bottom and heated by a DC supply unit (Aplab L 6405). At the top section, the condenser, cooling was provided by blowing conditioned air at $25^{\circ} \mathrm{C}$ using an electric fan.

However, a combination of glass copper tubes (ID 2 $\mathrm{mm}$ and OD $3 \mathrm{~mm}$ ) were also attempted for PHP using silicon tube for connecting glass and copper tubes, but the junction could not sustain at above $30 \mathrm{~W}$ heat input and thus did not work successfully. Agilent 34970 A multiplexer, resolution $0.01{ }^{\circ} \mathrm{C}$ was used to record the experimental data. The system was kept under vacuum up to $10^{-4}$ mbar.

\subsection{Experimental Method}

Air was extracted by applying a vacuum of $10^{-4}$ mbar for 7 - 8 hours. Desired quantity of working fluid was filled in using syringe pump. Conditioned air was maintained at $25^{\circ} \mathrm{C}$. DC power unit was switched on and heating power was adjusted at $5 \mathrm{~W}$. Temperature at different locations was recorded with the help of $\mathrm{J}$ type thermocouples which were connected to the data acquisition system. After the temperature became constant, the heating power was increased to $10 \mathrm{~W}, 15 \mathrm{~W} \cdots 100 \mathrm{~W}$. The same procedure was repeated for filling ratio (ratio of volume of liquid charged to the total volume of PHP) ranging from $10 \%$ to $100 \%$.

Above procedure was repeated for PHP oriented horizontally and inclined at $45^{\circ}$. The measured temperature from the thermocouple at the adiabatic section centre was used as the saturated steam temperature i.e. the operating temperature.

\section{Result and Discussions}

\subsection{Minimum Startup Power}

Mainly two parameters are used to evaluate the performance of PHP, start-up power and thermal resistance. The startup power is the minimum power needed by the PHP to get started [20]. When the PHP reaches the required startup condition, the oscillating motion in the PHP starts. And when the required superheat or/and input power meet the required condition, the stable oscillating motion can be self-sustained. The startup condition is very important for the stable oscillating motion occurring in a PHP. The startup depends on many factors like the filling ratio, tube geometry, wall temperature variation, heat flux level, physical properties of working fluid, heating and cooling modes, transient heat transfer process, initial temperature, and so on.

The startup power at different filling ratios were found out for both the working fluids. Table 2 summarizes the effect of filling ratio of the two working fluids on the
Table 2. Variation of start-up power with filling ratio for methanol and DI water.

\begin{tabular}{ccc}
\hline \multirow{2}{*}{ Filling Ratio (\%) } & \multicolumn{2}{c}{ Start-up power (W) } \\
\cline { 2 - 3 } & DI water & Methanol \\
\hline 20 & 25 & 30 \\
30 & 20 & 15 \\
40 & 20 & 15 \\
50 & 15 & 20 \\
60 & 15 & 20 \\
70 & 20 & 20 \\
80 & 25 & 25 \\
90 & 30 & 25 \\
\hline
\end{tabular}

startup power. Figure 2 shows the minimum startup power at $50 \%$ filling ratio for DI water and Figure 3 shows for methanol at $40 \%$ filling ratio. From Figures 2 and 3 , it can be seen that at a heat input of $5 \mathrm{~W}$, the temperature of evaporator increases and then becomes constant; as the heat input is increased further to $10 \mathrm{~W}$, the temperature again increases and reaches a constant value. When the heat input is increased to $15 \mathrm{~W}$, the temperature of evaporator increases and then a sharp decrease is observed, after which the device starts working in pulsating mode. Before the startup condition has reached, the pressure in the vapor bubble is not sufficient to drive the train of liquid plug and vapor bubble above it. After the achievement of startup condition, nucleate boiling starts in the heating section and the size of vapor bubbles grow, increasing its instant pressure and thus the pressure difference between the evaporator and the condenser section, which is the driving force for the oscillatory motion inside [20].

\subsection{Optimum Filling Ratio}

The optimum filling ratio with respect to the startup condition and thermal resistance was evaluated. From Table $\mathbf{2}$, it can be seen that for DI water, the startup power decreases as the filling ratio increases from $20 \%$ to $50 \%$. The start-up power for $50 \%$ and $60 \%$ filling ratio are the same, $15 \mathrm{~W}$, but the time to reach the start-up condition with $60 \%$ fill ratio was 1000 seconds as compared to 900 seconds for $50 \%$ filling ratio. Then after, as the filling ratio is increased, the startup power again increases. Similar trend was obtained for methanol, where the startup power decreases as the filling ratio increases from $10 \%$ to $30 \%$, it was minimum at $30 \%$ and $40 \%$ filling ratio $(15 \mathrm{~W})$, then further increases on increasing the filling ratio.

To know the most appropriate optimum filling ratio, the effect of filling ratio on the thermal resistance of PHP was also studied. Figures $\mathbf{4}$ and $\mathbf{5}$ show the effect of filling 


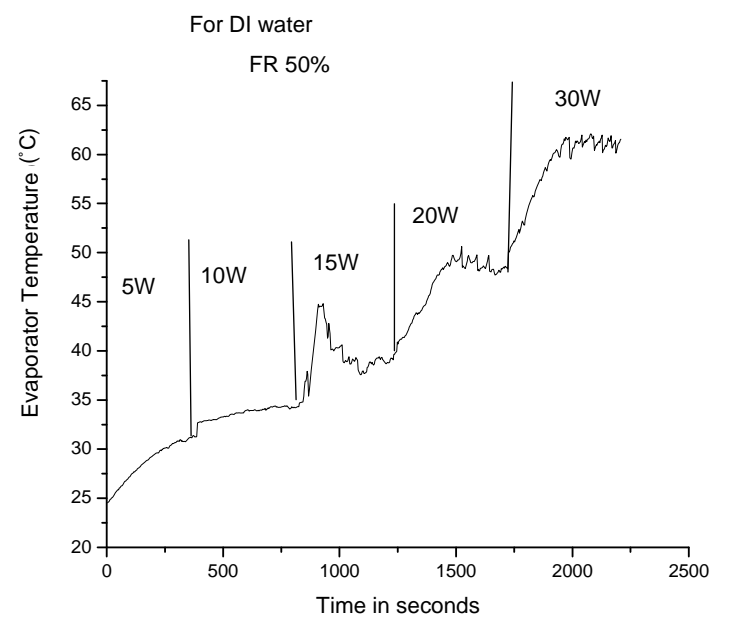

Figure 2. Transient variation of evaporator temperature with increasing heat input for vertically oriented PHP filled with deionised water at FR $50 \%$.

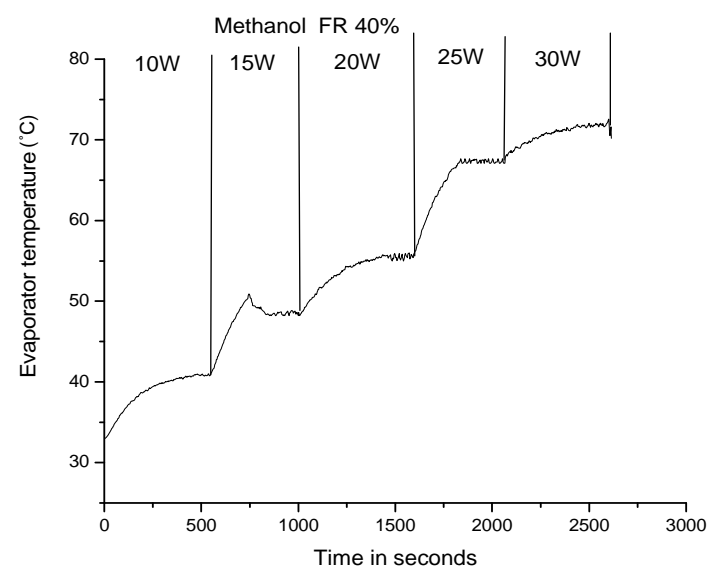

Figure 3. Transient variation of evaporator temperature with increasing heat input for vertically oriented PHP filled with methanol at FR $\mathbf{4 0} \%$.

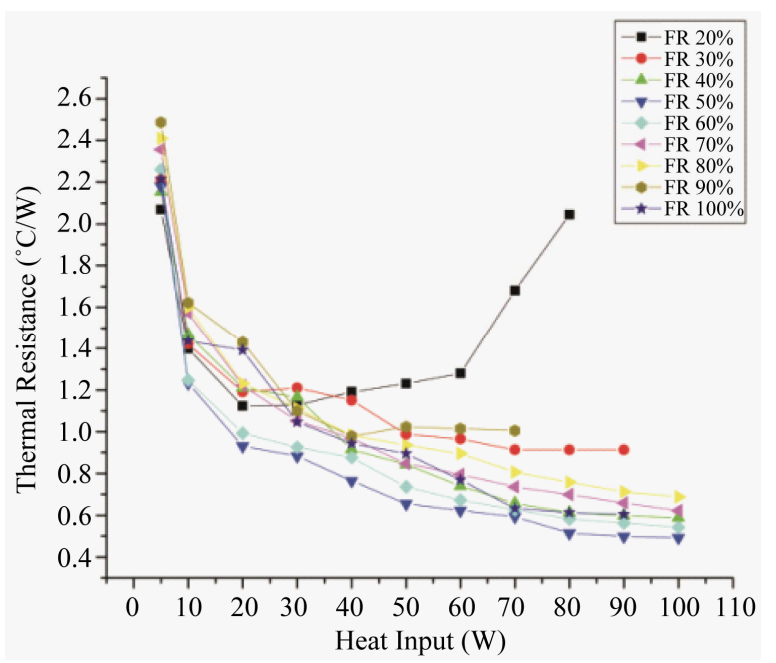

Figure 4. Effect of filling ratio on thermal resistance for DI water.

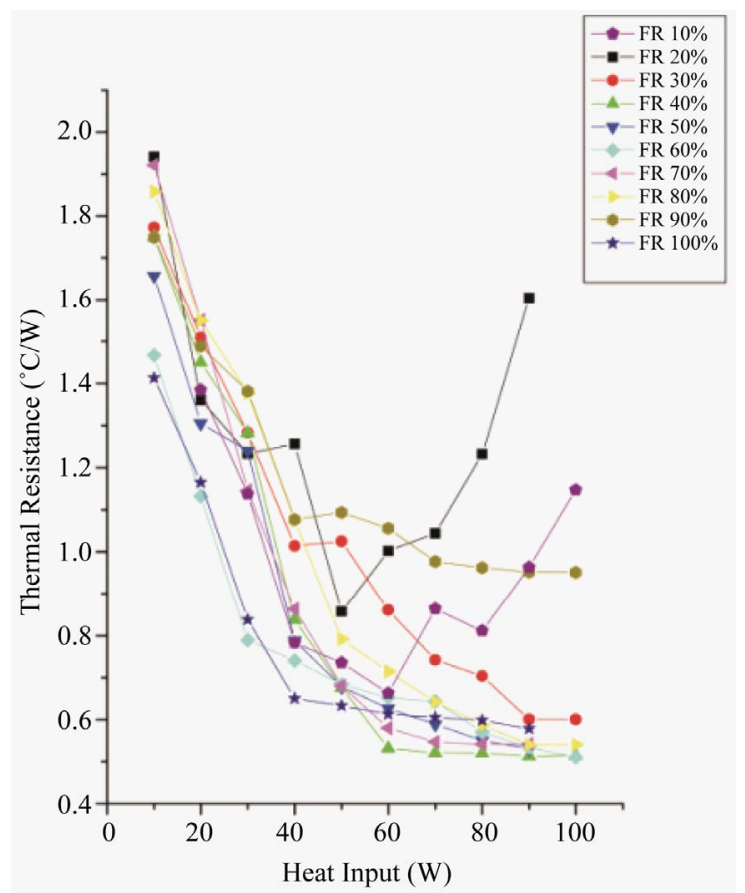

Figure 5. Effect of filling ratio on thermal resistance for Methanol.

ratio on the thermal resistance for PHP with DI water and methanol as working fluid. The thermal resistance of the PHP is defined as:

$$
R=\frac{T_{e}-T_{c}}{Q}
$$

where $T_{e}$ and $T_{c}$ being the average wall temperatures of the evaporator and condenser respectively and $Q$ is the input power.

From the Figure 4 it can be seen that at very low filling ratios, i.e. $20 \%$, thermal resistance increases with increasing power, but, as the power in increased beyond $40 \mathrm{~W}$ dry-out occurs. At low filling ratios, as the heat input is increased, the entire surface is covered by the vapor space which leads to dry-out situation. As the filling ratio increases further, the device starts acting in pulsating mode. For DI water, minimum resistance is offered at a filling ratio of $50 \%$ whose value is $0.492^{\circ} \mathrm{C} / \mathrm{W}$. As the filling ratio increase beyond $50 \%$, the thermal resistance offered by the device increases. At FR 90\% very few bubbles are present in the PHP, thus a remarkable drop in the performance is observed. At FR 100\%, when no bubbles are present, the heat transfer occurs solely by convection. In PHP vapor bubbles are supposed to pulse and promote the liquid slug and dispel the heat from evaporator to the condensation section. In the PHP high fill ratio is responsible to hinder the pulsation of the bubble and hence the efficiency of heat transfer will not be very good. The low filling ratios are expected to favour the pulsation of the bubble, but it is extremely easy 
to dry out. Thus $50 \%$ was chosen as the optimum filling ratio for DI water. Figure 5 shows the effect of filling ratio of methanol on PHP. Thus the minimum resistance, $0.51{ }^{\circ} \mathrm{C} / \mathrm{W}$ was obtained at $40 \%$ filling ratio and thus $40 \%$ was the optimum filling ratio for methanol. The performance of methanol is quite comparable to that of water. The thermodynamic properties of water make its performance better. Its high latent heat spreads more heat with less fluid flow. To compare the performance of both the working fluids the evaporator and condenser heat transfer coefficients were calculated at respective optimum filling ratios for both the fluids (Figure 6). The heat transfer coefficients can be calculated as:

$$
h_{e}=\frac{q_{e}}{T_{e}-T_{s}} ; h_{c}=\frac{q_{c}}{T_{s}-T_{c}} ; q_{e}=\frac{Q}{\pi d L_{e}} ; q_{c}=\frac{Q}{\pi d L_{c}}
$$

As seen from Figure 6, the heat transfer coefficient for water is more than that of methanol. The difference in evaporator side heat transfer coefficient is not much, but appreciable difference in condenser side heat transfer coefficient can be observed. This is because both $h_{e}$ and $h_{c}$ depend on saturation temperature of the fluid, which is more for water.

\subsection{Effect of Orientation}

Studies were also conducted to study the effect of working fluid on the working of PHP at different orientation. Figures 7 and 8 show the thermal resistance of PHP with water and methanol respectively, at different orientation. In case of water the minimum resistance at $45^{\circ}$ inclination is $0.55^{\circ} \mathrm{C} / \mathrm{W}$ while at horizontal orientation the value is $0.81^{\circ} \mathrm{C} / \mathrm{W}$. While when methanol is used as the working fluid, the minimum resistances are $0.51,0.52$ and $0.63^{\circ} \mathrm{C} / \mathrm{W}$ at vertical, $45^{\circ}$ inclination and horizontal orientation respectively. At horizontal orientation, in absence of gravity, the effect of surface tension dominates. The high surface tension of water creates additional fric-

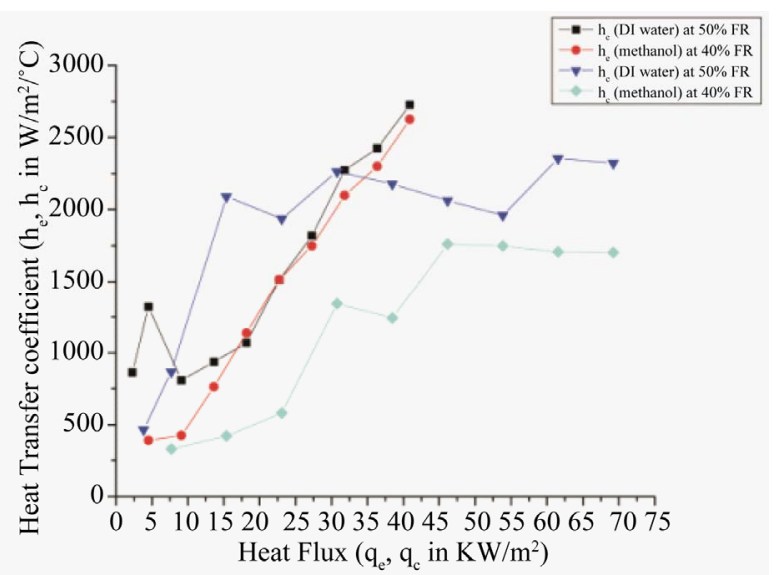

Figure 6. Heat transfer coefficient vs heat flux for DI water \& methanol.

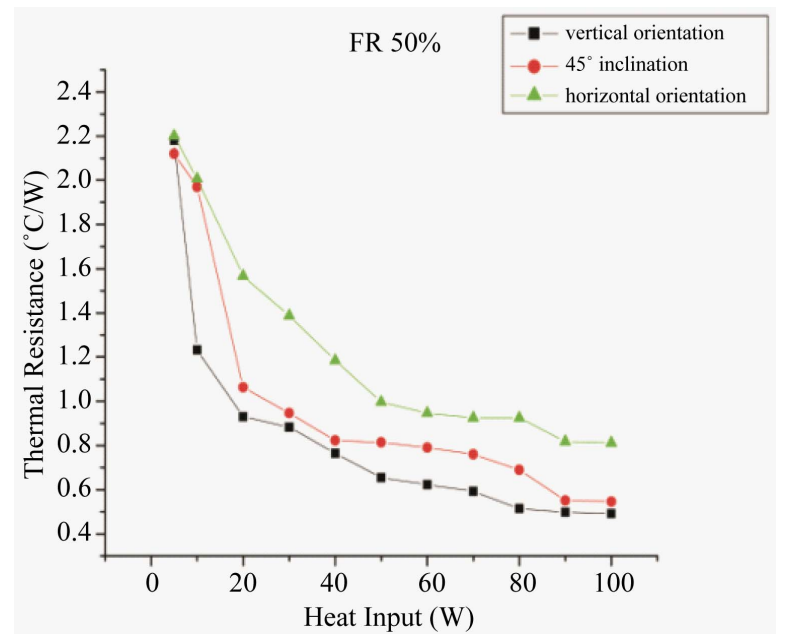

Figure 7. Effect of orientation on thermal resistance for DI water.

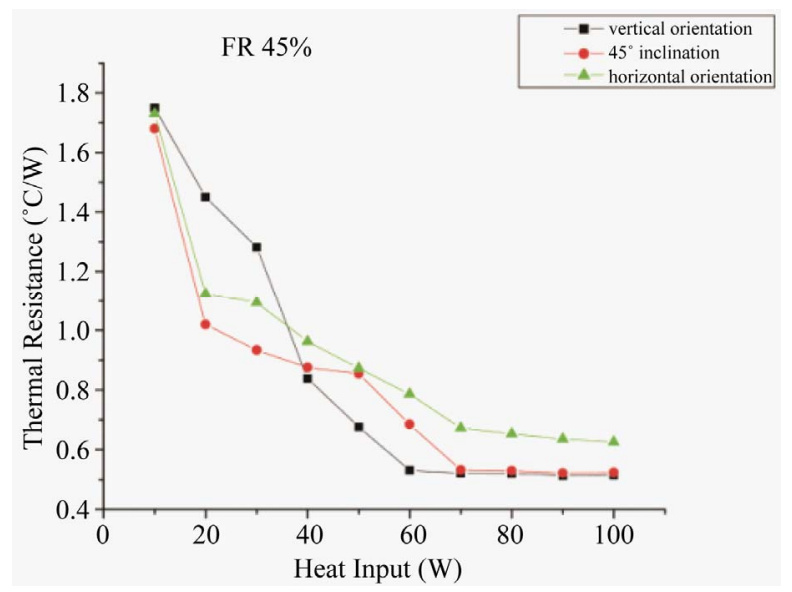

Figure 8. Effect of orientation on thermal resistance for methanol.

tion and restricts the two phase flow. This problem can be overcomed by the use of methanol, whose surface tension is quite low in comparison to water (about one-third). Thus the fluid with low surface tension gives better results. Thus by the use of methanol it can be said that the device becomes almost orientation free.

The effect of orientation on the startup temperature and the time required to reach were also studied. Figure 9 shows the startup temperature with time for DI water at $50 \%$ filling ratio and Figure 10 shows for methanol at $40 \%$ filling ratio. On comparing the performance of PHP in both the cases it can be seen that by using methanol as working fluid, the startup temperature and time can considerably be reduced. Approximately 300 seconds are required for PHP to reach startup with methanol while 750 seconds are required with DI water in vertical orienttation. Similarly, the startup time reduces to 560 seconds from 900 seconds in horizontal orientation and 360 seconds from 450 seconds at $45^{\circ}$ inclination, by the use of 


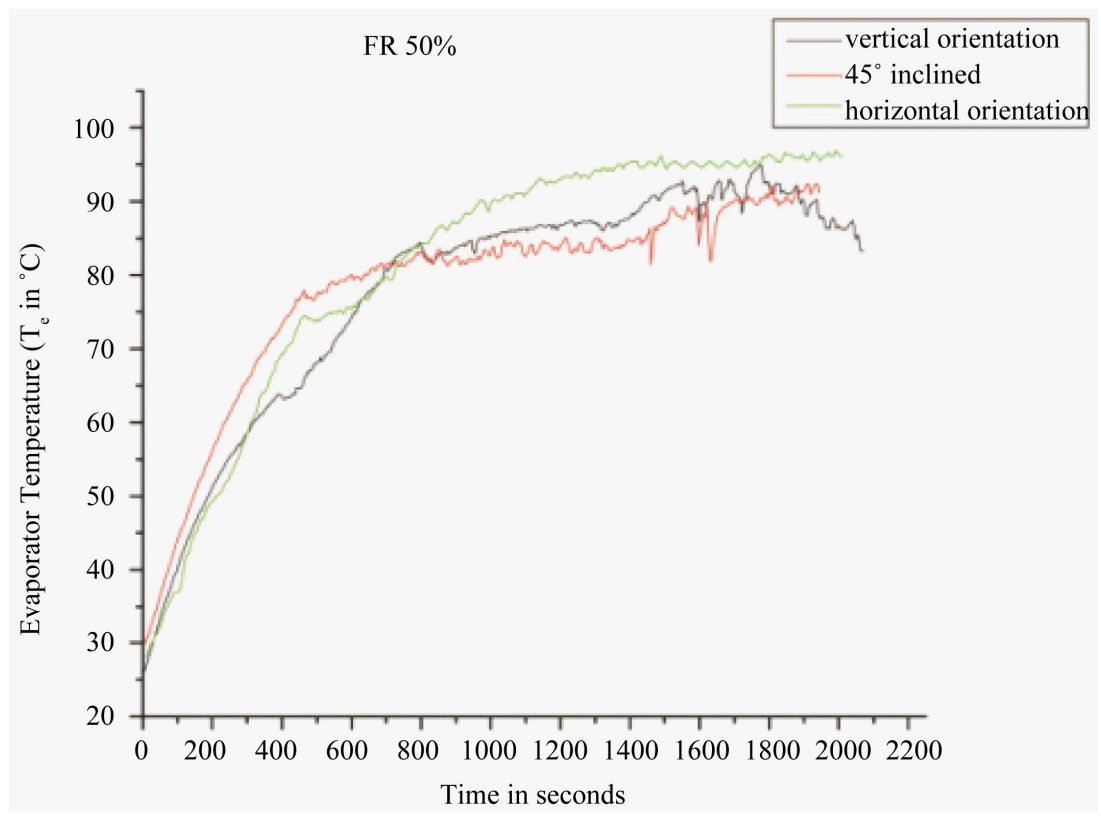

Figure 9. Effect of orientation on evaporator temperature for DI water at 50 W.

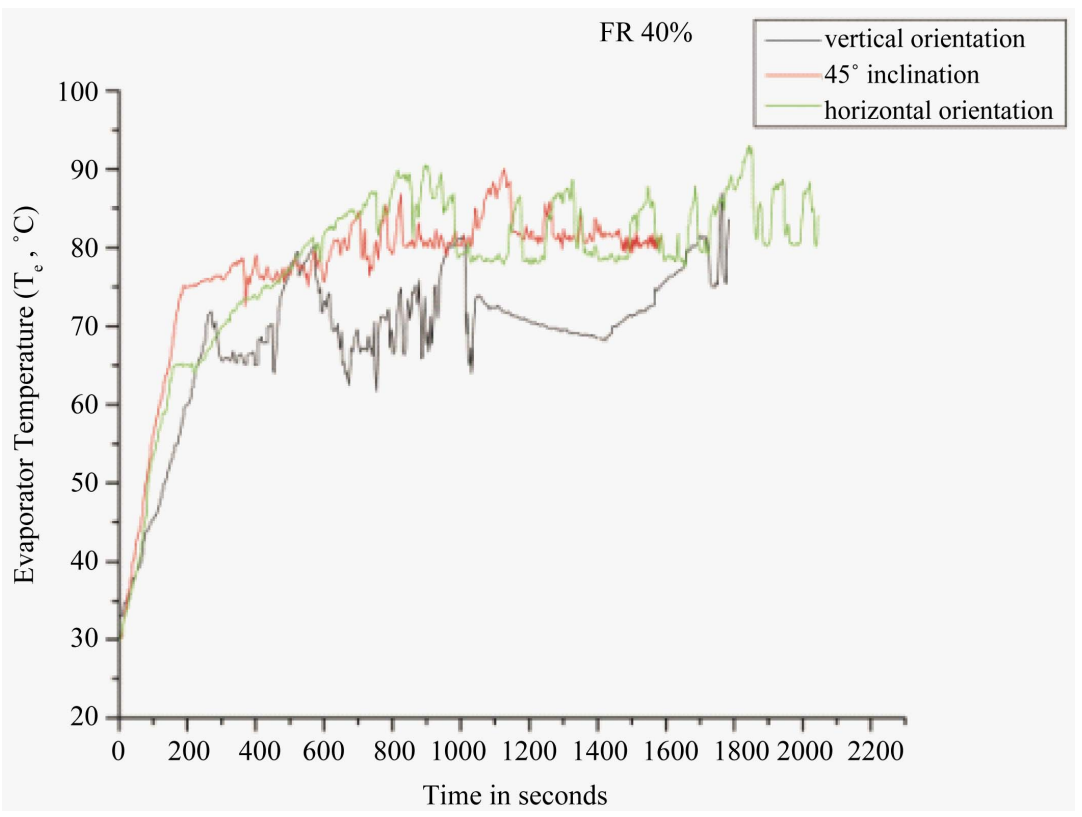

Figure 10. Effect of orientation on evaporator temperature for methanol at $50 \mathrm{~W}$.

methanol. The formation and departure of vapor nuclie from active sites is delayed when it is in horizontal orientation, whereas in vertical orientation, when the gravitational forces become dominating parameter, the convective heat transfer coefficient may increase resulting in augmentation in heat transfer in evaporator zone. Also high degree of pressure fluctuations were recorded with methanol. This is because of the fact that the saturation pressure of methanol is higher and this effect the spatial dynamic pressure perturbations helping minimize the gravity effect in vapor-slug system [17].

\section{Conclusion}

The experimental investigation shows that minimum start-up power for water as working fluid in PHP are at $50 \%$ and $60 \%$ filling ratio while for methanol as working fluid, they are at $30 \%$ and $40 \%$ filling ratio. The optimum filling ratio for a minimum thermal resistance was found to be $50 \%$ for water and $40 \%$ for methanol. In vertical orientation of PHP, the resistances observed are 0.492 and $0.51^{\circ} \mathrm{C} / \mathrm{W}$ for water and methanol respectively. Hence the optimum filling ratio was taken as $50 \%$ for 
water and $40 \%$ for methanol. The heat transfer coefficient on evaporator side, for both the liquids, was almost similar, while there was an appreciable difference in heat transfer coefficients on condenser side. The start-up temperature and startup time at all orientations can considerably be reduced by using methanol as working fluid in PHP. At optimum filling ratio, the minimum thermal resistance of water charged PHP at $45^{\circ}$ inclination and horizontal orientation was found to be $0.55^{\circ} \mathrm{C} / \mathrm{W}$ and $0.81^{\circ} \mathrm{C} / \mathrm{W}$ respectively while that of methanol charged $\mathrm{PHP}$, is $0.52^{\circ} \mathrm{C} / \mathrm{W}$ and $0.63^{\circ} \mathrm{C} / \mathrm{W}$ at $45^{\circ}$ inclination and horizontal orientation respectively. Hence it may be concluded that the PHP charged with methanol can be considered as orientation free.

\section{Acknowledgements}

Authors are grateful to AICTE, ND for sanctioning a research project to them.

\section{REFERENCES}

[1] H. Akachi, "Structure of a Heat Pipe," US Patent No 4921041, 1990.

[2] M. Groll and S. Khandekar, "Pulsating Heat Pipe: Progress and Prospects," Proceedings of International Conference on Energy and Environment, Shanghai, 11-13 December 2003, pp. 723-730.

[3] Y. Zhang and A. Faghri, "Advances and Unsolved Issues in Pulsating Heat Pipes," Heat Transfer Engineering, Vol. 29, No. 1, 2008, pp. 20-44. doi:10.1080/01457630701677114

[4] Y. Zhang and A. Faghri, "Heat Transfer in a Pulsating Heat Pipe with Open End," International Journal of Heat and Mass Transfer, Vol. 45, No. 4, 2002, pp. 755-764. doi:10.1016/S0017-9310(01)00203-4

[5] M. B. Shafii, A. Fagiri and Y. Zhang, "Thermal Modeling of Unlooped and Looped Pulsating Heat Pipes," ASME Journal of Heat Transfer, Vol. 123, No. 6, 2001, pp. 11591172. doi:10.1115/1.1409266

[6] T. Hudakorn, P. Terdtoon and P. Sakulchangsatjatai, "Effect of Inclination Angle on Performance Limit of a Closed-End Oscillating Heat Pipe," American Journal of Engineering and Applied Sciences, Vol. 1, No. 3, 2008, pp. 174-180. doi:10.3844/ajeassp.2008.174.180

[7] S. Nishio, "Oscillatory-Flow Heat-Transport Device (Forced Oscillatory Flow Type and Bubble Driven Type)," Proceedings of the 11th International Heat Pipe Conference, Tokyo, Vol. 2, 1999, pp. 39-49.

[8] M. Hosoda, S. Nishio and R. Shirakashi, "Meandering Closed Loop Heat Transport Tube (Propagation Phenomena of Vapor Plug)," Proceedings of the 5th ASME/JSME
Joint Thermal Engineering Conference, San Diego, 14-19 March 1999, pp. 1-6.

[9] B. Verma, V. L. Yadav and K. K. Srivastava, "Nanofluid-An Alternative Fluid in Pulsating Heat Pipe/Oscillating Heat Pipe," IOSR Journal of Electronics and Communication Engineering, Vol. 3, No. 3, 2012, pp. 28-37. doi: 10.9790/2834-0332837

[10] S. Khandekar, N. Dollinger and M. Groll, "Understanding Operational Regimes of Closed Loop Pulsating Heat Pipes: An Experimental Study," Applied Thermal Engineering, Vol. 23, No. 6, 2003, pp. 707-719. doi:10.1016/S1359-4311(02)00237-5

[11] S. Liu, J. Li, X. Dong and H. Chen, "Experimental Study of Flow Patterns and Improved Configurations for Pulsating Heat Pipes," Journal of Thermal Science, Vol. 6, No. 1, 2007, pp. 56-62. doi:10.1007/s11630-007-0056-8

[12] L. Lin, R. Ponnappan and J. Leland, "Heat Transfer Characteristics of an Oscillating Heat Pipe," Proceedings of the 34th AIAA Thermophysics Conference, Denver, 2000, pp. 2000-2281.

[13] L. Lin, R. Ponnappan and J. Leland, "Experimental Investigation of Oscillating Heat Pipes," AIAA Journal of Thermophysics and Heat Transfer, Vol. 15, No. 4, 2001, pp. 395-400. doi: $10.2514 / 2.6641$

[14] R. R. Riehl, "Characteristics of an Open Loop Pulsating Heat Pipe," Proceedings of the 34th International Conference on Environmental Systems, Colorado Springs, 1921 July 2004.

[15] B. Y. Tong, T. N. Wong and K. T. Ooi, "Closed Loop Pulsating Heat Pipe," Applied Thermal Engineering, Vol. 21, No. 18, 2001, pp. 1845-1862. doi:10.1016/S1359-4311(01)00063-1

[16] J. L. Xu and X. M. Zhang, "Start-Up and Steady Thermal Oscillation of a Pulsating Heat Pipe," Heat Mass Transfer, Vol. 41, No. 8, 2005, pp. 685-694. doi:10.1007/s00231-004-0535-3

[17] M. Vassilev, Y. Avenas, C. Schaeffer, J. L. Schanen and J. S. Harder, "Experimental Study of a Pulsating Heat Pipe with Combined Circular and Square Section Channels," Proceedings of the 42nd IAS Annual Meeting Conference, New Orleans, 23-27 September 2007, pp. 1419-1425.

[18] C. Hu and L. Jia, "Experimental Study on the Startup Performance of Flat Plate Pulsating Heat Pipe," Journal of Thermal Sciences, Vol. 20, No. 2, 2011, pp.150-154. doi:10.1007/s11630-011-0450-0

[19] X. Wang, T. Han, L. Wang, X. Mao and C. Yang, "Experimental Study on Startup Characteristics of Pulsating Heat Pipe," Advanced Materials Research, Vol. 354, 2012, pp. 87-91. doi:10.4028/www.scientific.net/AMR.354-355.87

[20] W. Qu and H. B. Ma, "Theoretical Analysis of Startup of a Pulsating Heat Pipe," International Journal of Heat and Mass Transfer, Vol. 50, No. 11-12, 2007, pp. 2309-2316. doi:10.1016/j.ijheatmasstransfer.2006.10.043 


\section{Abbreviations and Nomenclatures}

DI: de-ionized;

$R$ : thermal resistance $\left({ }^{\circ} \mathrm{C} / \mathrm{W}\right)$;

$F R$ : filling ratio;

$Q$ : heat input (W);

$T_{e}$ : evaporator temperature $\left({ }^{\circ} \mathrm{C}\right)$;

$h$ : heat transfer coefficient $\left(\mathrm{W} / \mathrm{m}^{2} /{ }^{\circ} \mathrm{C}\right)$;

$T_{c}$ : condenser temperature $\left({ }^{\circ} \mathrm{C}\right)$; $q$ : heat flux $\left(\mathrm{kW} / \mathrm{m}^{2}\right)$;

$T_{\text {sat }}:$ saturation temperature $\left({ }^{\circ} \mathrm{C}\right)$;

$\mathrm{d}$ : internal diameter $(\mathrm{m})$;

$L_{e}$ : length of evaporator section (m);

$L_{c}$ : length of condenser section (m);

$P_{\text {sat }}$ : Pressure at saturation $\left(\mathrm{N} / \mathrm{m}^{2}\right)$;

$\sigma$ : Surface tension $(\mathrm{N} / \mathrm{M})$;

$\rho$ : density $\left(\mathrm{kg} / \mathrm{m}^{3}\right)$. 